\title{
3 Research Square \\ Scientific Production in Cerebrospinal Fluid Leak (Rhinorrhea and Otorrhea) from 1945 to 2018
}

Irene Monjas-Canovas

Alicante General University Hospital: Hospital General Universitari d'Alacant

Jose-Manuel Ramos-Rincon ( $\square$ jose.ramosr@umh.es )

Miguel Hernandez University of Elche Faculty of Medicine: Universidad Miguel Hernandez de Elche Facultad de Medicina https://orcid.org/0000-0002-6501-9867

Javier Abarca-Olivas

general hospital alicante

Juan-Ramón Gras-Albert

independent research

Isabel Belinchón Romero

Miguel Hernandez University of Elche Faculty of Medicine: Universidad Miguel Hernandez de Elche

Facultad de Medicina

Gregorio González-Alcaide

University of Valencia: Universitat de Valencia

\section{Research article}

Keywords: Bibliometric, Publications, cerebrospinal fluid leak, cerebrospinal fluid rhinorrhea, cerebrospinal fluid otorrhea

Posted Date: November 24th, 2020

DOI: https://doi.org/10.21203/rs.3.rs-112568/v1

License: (c) (i) This work is licensed under a Creative Commons Attribution 4.0 International License.

Read Full License 


\section{Abstract}

BACKGROUND: To analyze research activity on cerebrospinal fluid (CSF) leaks in general and CSF rhinorrhea and otorrhea in particular, and to identify the main topic clusters in these areas.

METHODS: We identified all documents using the medical subject heading "Cerebrospinal Fluid Leak" indexed in the MEDLINE database between 1945 and 2018. We performed a descriptive bibliometric analysis and analyses of networks and research clusters in order to identify the main topic areas of research.

RESULTS: From 1945 to 2018 a total of 4130 records were published with the term CSF, including 2821 documents $(68.1 \%)$ with the term CSF rhinorrhea and 1040 documents $(25.8 \%)$ with CSF otorrhea. The number of documents published increased from 10 in 1945-49 to 642 in 2010-14. Articles were the dominant document type ( $86.8 \%$ of the documents analyzed), while case reports were the main type of study (37.4\%). In terms of geographic distribution, researchers from the United States of America (USA) led in the number of signatures (39.06\%), followed by those from the United Kingdom (UK) $(7.49 \%)$. The most active areas of research in the field were "Postoperative Complications," "Tomography, X-Ray Computed," and "Magnetic Resonance Imaging." The terms "Adults," "Young Adult," and "Middle Aged" were most common in CSF rhinorrhea research; and the terms "Infant," "Child, Preschool," "Child," and "Adolescent" were more common in CSF otorrhea.

CONCLUSIONS: Articles and case reports related with "Surgery" and "Postoperative Complications" associated with diagnosis are the main topic of study, highlighting the importance of this document type in advancing knowledge.

\section{Background}

Cerebrospinal fluid (CSF) leak is a discharge of cerebrospinal fluid through a hole in the skull bone, most commonly draining from the nose (CSF rhinorrhea) or from the ear (CSF otorrhea), occurring either through the external auditory meatus or through the eustachian tube into the nasopharynx) [21]. Common etiologies of CSF rhinorrhea include trauma, neoplasms, and prior surgery, while CSF otorrhea is usually associated with craniocerebral trauma, neurosurgical procedures or other conditions; however, both conditions may occur spontaneously [9]

The past few decades have seen an increase in research publications in the field of otorhinolaryngology [8] Bibliometrics, too, has consolidated as a discipline enabling the analysis of scientific activity in a particular field or area of knowledge through the quantification of the bibliographic characteristics of scientific publications [5] Several studies have analyzed the scientific production of otorhinolaryngology and head-neck surgery $[3,17,18]$ and neurosurgery $[1,2,7,11,15,16,23]$. Moreover, there are several publications focusing specifically on the activity in different countries, including African countries [1]. Other manuscript analyze specific research topics neurosurgery, like central nervous system arteriovenous malformations [15], idiopathic intracranial hypertension [16], endoscopic third 
ventriculostomy [23] carotid artery stenting [2] pituitary adenoma [7] o IDEAL framework in neurosurgery [11]

One of the areas that has seen significant development within bibliometrics is the generation of visual representations, networks and maps of scientific activity [5]. These have great analytic potential, helping to characterize the structures, groupings and interconnections between the elements under analysis, including the descriptors assigned to the documents, such as in the present study. Although bibliometric indicators have been used to approach the study of numerous diseases $[5,6]$, this methodology has not been applied to research on the well-known condition of CSF, which encompasses surgical, diagnostic, and therapeutic-radiological aspects, among others.

The aim of this study is to describe the scientific production on CSF leak through bibliometric indicators, using the documents indexed in the MEDLINE database between 1945 and 2018. We analyze the evolution in the number of publications, the publication types, the document categories of clinical interest, the journals of publication, the geographic distribution of the research and the topics addressed according to the different types of CSF leak (CSF rhinorrhea and CSF otorrhea) by means of co-word maps.

\section{Methods}

\section{Identification of documents on "Cerebrospinal Fluid Leak"}

The first step of this study was to identify the documents about CSF leak in the MEDLINE database, the main database of reference for researchers and professionals in the health sciences. It is an open access resource that permits, through the use of the medical subject headings $(\mathrm{MeSH})$ thesaurus, the precise identification of documents that address the concepts under analysis as well as the contents of those documents. The CSF leak descriptor was included in 2005. This term encompasses the specific terms "Cerebrospinal Fluid Rhinorrhea" and "Cerebrospinal Fluid Otorrhea," both included in 1966. The searches of indexed documents with any of these three descriptors took place on the Clarivate Analytics Web of Science (WOS) platform, which includes the MEDLINE database, on January 21, 2019.

The Clarivate Analytics WOS platform provides information on the institutional affiliation of all authors. With this strategy, 4155 documents were retrieved, but we excluded 25 editorials, leaving 4130 documents to be analyzed. The analysis of the scientific production by country was limited to the 3019 documents (73.1\%) included in WOS database.

\section{Standardization of bibliographic information}

Using the bibliographic information from the retrieved documents, we created a relational database to standardize the bibliographic data and calculate the study variables, with special attention to the following fields: 
- Publication type (field: Publication Type). Based on the information collected from this field, we classified the records according to the document types (articles, reviews and letters) as well as the clinical approach (case reports, clinical trials, controlled clinical trials, evaluation studies, metaanalysis, observational studies, practice guidelines, randomized clinical trials, and validation studies).

- Institutional affiliation of papers included in WOS (field: Author Address). This field includes information relating to the institutional affiliation of the authors signing the documents. Although all institutional affiliations have been available for papers published in MEDLINE since 2014, we aimed to study and present the information using a standard approach, so we limited the analysis to the papers included in the WOS.

- Descriptors (fields: MeSH Terms [MH] and MeSH Subheadings (also called qualifiers) [SH]). We differentiated the MeSH from the subheadings or topic qualifiers (82 auxiliary descriptors that specify the aspect being addressed in relation to the MeSH terms) and identified the descriptors assigned with respect to CSF leak, CSF rhinorrhea, and CSF otorrhea.

\section{Calculation of indicators}

\section{A) Bibliometric indicators on scientific production}

To analyze the scientific activity of the area, we determined the number of documents published each year, the journal of publication, the document types, the clinical approach to the study, and the countries of the authors signing the documents. This information generates a picture of the scientific activity, the media used (scientific journals), and the weight of countries leading the research-in general and according to the different types of CSF (rhinorrhea or otorrhea).

\section{B) Topic analysis}

To characterize the research in the area at a topic level, we determined the frequency with which the descriptors assigned to the documents appeared for each group: the generic CSF leak group and the specific document groups on CSF rhinorrhea and CSF otorrhea. We constructed topic maps to analyze the relationship between the descriptors and the research groups around them, that is, the existing research clusters, approaches, and specializations. This process had the following steps:

- Determination of the co-occurrence of the descriptors assigned to the documents and generation of a matrix of absolute values. The joint assignment of two descriptors in a single document implies a thematic affinity, as both aspects are addressed simultaneously in the same paper.

- Elimination of generic descriptors. We eliminated some excessively generic descriptors that did not describe relevant information on content or that presented a high density of relationships with the rest of the descriptors. 
- Visual representation of the network. To establish the existing topic clusters in the area and represent them visually, we used a clustering algorithm in the VOSViewer program, which helps to detect the communities (clusters) within a network, made up of groups of homogeneous items that are strongly related to each other [21].

\section{Statistical analysis}

We compared the MeSH terms in CSF rhinorrhea and CSF otorrhea documents using the Chi-squared test. $P$ values of less than 0.05 were considered statistically significant. We used statistical software SPSS version 22.0 for analysis.

\section{Ethical considerations}

Due to the nature of the study and dataset, it was not necessary to obtain informed consent or approval from an institutional ethics committee

\section{Results}

\section{Bibliometric indicators}

\section{Evolution of production}

From 1945 to 2018,4130 articles were published with the CSF leak terms. The term CSF rhinorrhea was in 2821 documents (68.1\%) and CSF otorrhea, in 1040 (25.8\%). Both terms were present in 316 documents, while 269 documents used only the generic CSF leak descriptor. Figure 1 shows the evolution of the number of documents published on CSF leak.

\section{Publication type distribution}

The main publication type was article, which encompassed $86.8 \%(n=3584)$ of the documents; followed at a considerable distance by review, which made up 9.4\% $(n=390)$; and letter, at 3.8\% $(n=156)$. With regard to the type of clinical research, $37.4 \%(n=1544)$ of the documents were case reports; $1.7 \%(n=74)$, clinical trials; $0.6 \%(n=48)$, evaluation studies; and $0.5 \%(n=19)$, meta-analyses. The rest of the study types presented only negligible values (10 observational studies, 8 validation studies, and 2 practice guidelines).

\section{Journal distribution and thematic categories}

The documents were published in 735 different journals. The main journals were World Neurosurgery/Surgical Neurology $(n=178)$, Laryngoscope $(n=176)$, Journal of Neurosurgery $(n=134)$, Otology \& Neurotology/American Journal of Otology $(\mathrm{n}=124)$, and Otolaryngology-Head and Neck Surgery $(n=101)$. These five journals published $16.8 \%$ of the documents. Moreover, there were 371 journals with just one document, which together represented $9.0 \%$ of the total. Table 1 presents details of the top 17 journals at least $1.0 \%$ of the total documents on CSF leak. About three-quarters of the 
documents $(n=3019,73.1 \%)$ were published in journals included in the WOS Journal Citation Reports. The three main WOS categories were Otorhinolaryngology (29.3\%), Surgery (20.7\%), and Clinical Neurology (19.8\%), followed by Medicine, General \& Internal (5.9\%) and Radiology, Nuclear Medicine \& Medical Imaging (5.2\%). 
Table 1

The 17 top-ranking journals ( $\geq 1 \%$ research production) in research production on cerebrospinal fluid leak

\section{Top 15 journals}

World Neurosurgery/Surgical

Neurology*

Laryngoscope

\section{N \%}

docs docs
Impact

factor

2018

$178 \quad 4.3 \quad 1.723 \quad$ Clinical Neurology (151/199)

Surgery $(111 / 203)$

$176 \quad 4.1 \quad 2.343$

Medicine. Research \&
Journal category (ranking, 2018)

Experimental Medicine (78 of 136)

Otorhinolaryngology (12 of 42)

$134 \quad 3.1 \quad 4.204 \quad$ Clinical Neurology (41/199)

$\begin{array}{llll}124 & 3.0 & 2.063 \quad \text { Clinical Neurology (134/199) }\end{array}$

Otorhinolaryngology (21/42)

$\begin{array}{llll}101 & 2.3 & 2.310 \quad \text { Otorhinolaryngology (13/42) }\end{array}$

Surgery $(72 / 203)$

Otorhinolaryngology (33/42)

Journal of Laryngology and Otology 88

Acta Neurochirurgica

$\begin{array}{lll}86 & 2.0 & 1.834\end{array}$

Clinical Neurology (146/199)

Surgery $(106 / 203)$

Neurosurgery

$85 \quad 2.0$

4.853

Clinical Neurology (31/199)

Surgery (12/203)

Journal of Craniofacial Surgery

$57 \quad 1.3$

0.785

Surgery $(181 / 203)$

British Journal of Neurosurgery

$\begin{array}{lll}53 & 1.2 & 1.481\end{array}$

Clinical Neurology (165/199)

Surgery $(130 / 203)$

Otolaryngologic Clinics of North America

Annals of Otology, Rhinology, and Laryngology

\section{$\begin{array}{llll}50 & 1.2 & 1.620 & \text { Otorhinolaryngology (20/42) }\end{array}$}

49

$1.1 \quad 1.458$

Otorhinolaryngology (23/42)

* World Neurosurgery was called Surgical Neurology until 2010.

** Otology \& Neurotology was called American Journal of Otology 2012.

***Impact Factor from2009.

Nl: not included in Journal Citation Reports 


\begin{tabular}{|c|c|c|c|c|}
\hline \multirow[t]{2}{*}{ Top 15 journals } & \multirow[t]{2}{*}{$\begin{array}{l}\mathrm{N} \\
\text { docs }\end{array}$} & \multirow[t]{2}{*}{$\begin{array}{l}\% \\
\text { docs }\end{array}$} & $\begin{array}{l}\text { Impact } \\
\text { factor }\end{array}$ & \multirow[t]{2}{*}{ Journal category (ranking, 2018) } \\
\hline & & & 2018 & \\
\hline \multirow{2}{*}{$\begin{array}{l}\text { International Journal of Pediatric } \\
\text { Otorhinolaryngology }\end{array}$} & \multirow[t]{2}{*}{47} & \multirow[t]{2}{*}{1.1} & \multirow[t]{2}{*}{1.225} & Otorhinolaryngology (34/42) \\
\hline & & & & Pediatrics $(89 / 125)$ \\
\hline \multirow{2}{*}{$\begin{array}{l}\text { No Shinkei Geka. Neurological } \\
\text { Surgery }\end{array}$} & \multirow[t]{2}{*}{43} & \multirow[t]{2}{*}{1.0} & \multirow[t]{2}{*}{$0.131 * \star \star$} & Neuroscience (146/197) \\
\hline & & & & Surgery $(106 / 203)$ \\
\hline HNO & 43 & 1.0 & 0.914 & Otorhinolaryngology (37/42) \\
\hline Ear, Nose \& Throat Journal & 43 & 1.0 & 1.375 & Otorhinolaryngology (27/42) \\
\hline $\begin{array}{l}\text { Annales d'Oto-laryngologie et de } \\
\text { Chirurgie Cervico-faciale }\end{array}$ & 43 & 1.0 & $\mathrm{NI}$ & \\
\hline \multicolumn{5}{|c|}{ * World Neurosurgery was called Surgical Neurology until 2010.} \\
\hline \multicolumn{5}{|c|}{ ** Otology \& Neurotology was called American Journal of Otology 2012.} \\
\hline \multicolumn{5}{|l|}{$\star \star \star$ Impact Factor from 2009.} \\
\hline \multicolumn{5}{|c|}{ Nl: not included in Journal Citation Reports } \\
\hline
\end{tabular}

\section{Geographical distribution}

Of the 3019 included in WOS, 2578 showed the country of the institution writing the manuscript. Table 2 shows the number of documents published on CSF by the 15 most productive countries, both as a total and by type of CSF. Only 160 of the 2578 documents with country data (6.21\%) show evidence of international collaboration. The leading country in total scientific production on CSF-as well as specific production on CSF rhinorrhea and CSF otorrhea-is the United States of America (USA), followed by the United Kingdom (UK). The other countries with the largest research contributions were Japan, Germany, Italy, and France, with little difference between CSF rhinorrhea and CSF otorrhea.

Table 2. Top 15 countries producing research on cerebrospinal fluid (CSF) leak, CSF rhinorrhea and CSF otorrhea (1945-2018), included in the Web of Science and providing institutional data 


\begin{tabular}{|c|c|c|c|c|c|c|c|c|}
\hline \multicolumn{3}{|c|}{$\begin{array}{l}\text { All documents* } \\
(\mathrm{n}=\mathbf{2 5 7 8})\end{array}$} & \multicolumn{3}{|c|}{$\begin{array}{c}\text { CSF rhinorrhea } \\
(\mathbf{n}=1619)\end{array}$} & \multicolumn{3}{|c|}{$\begin{array}{c}\text { CSF otorrhea } \\
(n=585)\end{array}$} \\
\hline Country & $\begin{array}{l}\text { Nof } \\
\text { docs }\end{array}$ & $\begin{array}{l}\% \text { of } \\
\text { docs }\end{array}$ & Country & $\begin{array}{l}N \text { of } \\
\text { docs }\end{array}$ & $\%$ of docs & Country & $\begin{array}{l}\text { N of } \\
\text { docs }\end{array}$ & $\begin{array}{l}\% \text { of } \\
\text { docs }\end{array}$ \\
\hline USA & 1007 & 39,06 & USA & 612 & 37.8 & USA & 245 & 41.8 \\
\hline UK & 193 & 7.49 & UK & 118 & 7.29 & UK & 61 & 10.43 \\
\hline Japan & 166 & 6.44 & Germany & 113 & 6.98 & Germany & 46 & 7.86 \\
\hline Germany & 142 & 5.51 & Japan & 86 & 5.31 & Japan & 28 & 4.79 \\
\hline Italy & 128 & 4.96 & Italy & 83 & 5.13 & France & 26 & 4.44 \\
\hline France & 110 & 4.27 & France & 79 & 4.88 & Italy & 18 & 3.08 \\
\hline China & 101 & 3.92 & Turkey & 71 & 4.38 & Canada & 16 & 2.73 \\
\hline Turkey & 99 & 3.84 & India & 64 & 3.95 & South Korea & 13 & 2.22 \\
\hline India & 87 & 3.37 & China & 47 & 2.9 & Switzerland & 12 & 2.05 \\
\hline Canada & 63 & 2.44 & Switzerland & 42 & 2.59 & Turkey & 12 & 2.05 \\
\hline South Korea & 60 & 2.33 & Canada & 40 & 2.47 & China & 12 & 2.05 \\
\hline Spain & 57 & 2.21 & Spain & 38 & 2.35 & Spain & 11 & 1.88 \\
\hline Switzerland & 54 & 2.09 & Australia & 35 & 2.16 & India & 11 & 1.88 \\
\hline Australia & 46 & 1.78 & South Korea & 32 & 1.98 & Israel & 11 & 1.88 \\
\hline Brazil & 44 & 1.71 & Brazil & 29 & 1.79 & Australia & 10 & 1.71 \\
\hline
\end{tabular}

UK: United Kingdom, USA: United States of America

* The totals in this column are smaller than those of CSF rhinorrhea and CSF otorrhea, because a one documents can be included in both $\mathrm{MeSH}$

\section{Topic analysi}

\section{MeSH distribution}

The three principal MeSH terms in the field were "Postoperative Complications," "Tomography, X-Ray Computed," and "Magnetic Resonance Imaging." MeSH terms that were significantly more common in documents relating to CSF rhinorrhea compared to CSF otorrhea were "Magnetic Resonance Imaging," "Treatment Outcome," “Endoscopy," "Dura Mater," "Neurosurgical, Procedures," "Pituitary Neoplasms," and "Sphenoid Sinus." The terms "Meningitis," "Recurrence," "Ear, Inner," "Neuroma, Acoustic," "Mastoid," and "Otitis Media" appeared more frequently in relation to CSF otorrhea (Table 3). 
Table 3

Top descriptors (medical subject headings, MeSH) and qualifiers assigned to papers on cerebrospinal fluid (CSF)leak, CSF rhinorrhea and CSF otorrhea (1945-2018)

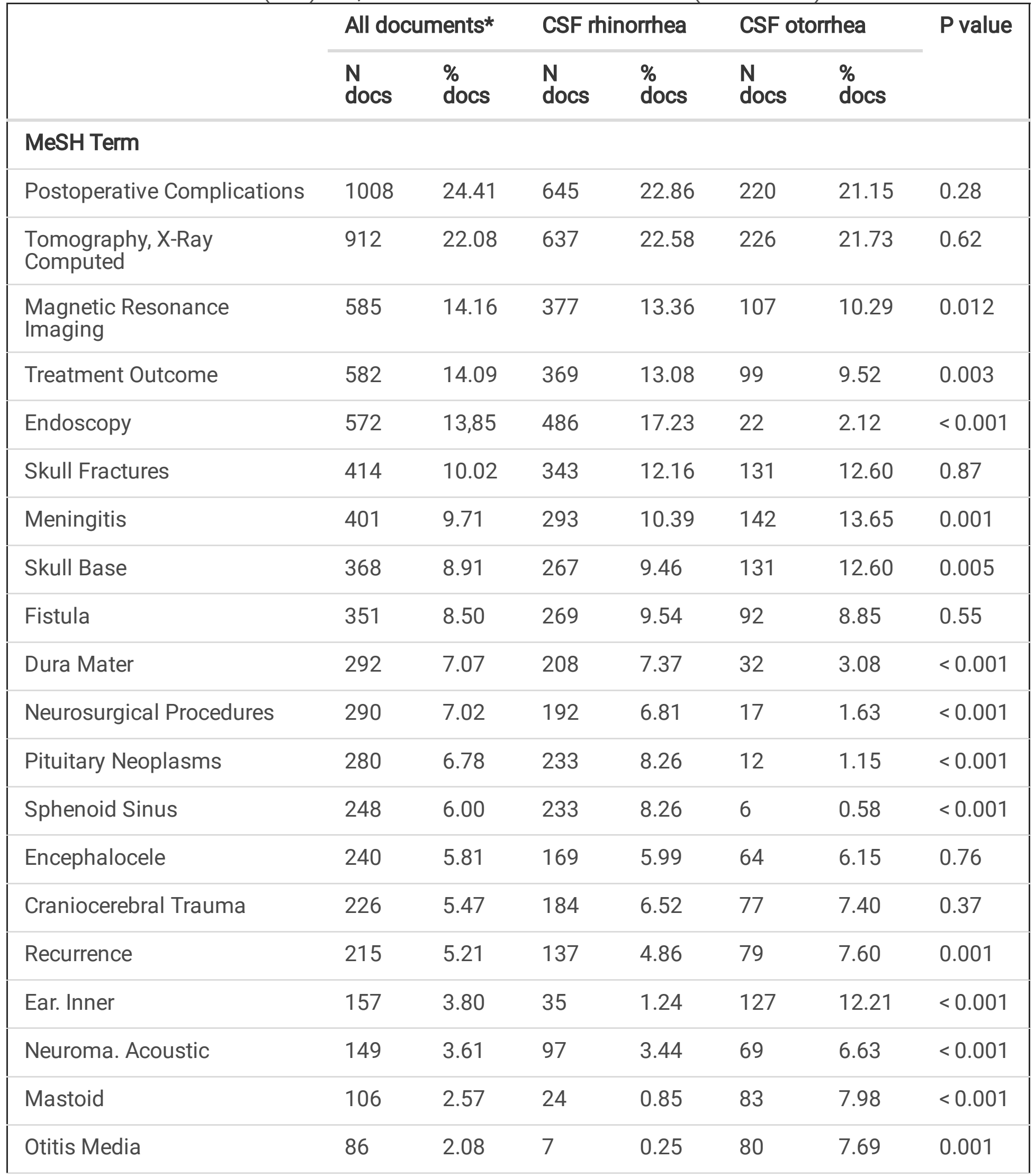

* The totals in this column are smaller than those of CSF rhinorrhea and CSF otorrhea, because a one documents can be included in both $\mathrm{MeSH}$ 


\begin{tabular}{|c|c|c|c|c|c|c|c|}
\hline & \multicolumn{2}{|c|}{ All documents* } & \multicolumn{2}{|c|}{ CSF rhinorrhea } & \multicolumn{2}{|c|}{ CSF otorrhea } & \multirow[t]{2}{*}{$P$ value } \\
\hline & $\begin{array}{l}\mathrm{N} \\
\text { docs }\end{array}$ & $\begin{array}{l}\% \\
\text { docs }\end{array}$ & $\begin{array}{l}\mathrm{N} \\
\text { docs }\end{array}$ & $\begin{array}{l}\% \\
\text { docs }\end{array}$ & $\begin{array}{l}\mathrm{N} \\
\text { docs }\end{array}$ & $\begin{array}{l}\% \\
\text { docs }\end{array}$ & \\
\hline \multicolumn{8}{|l|}{ Qualifiers } \\
\hline Surgery & 2540 & 61.5 & 1758 & 62.32 & 566 & 54.42 & $<0.001$ \\
\hline Etiology & 2444 & 59.18 & 1622 & 57.5 & 631 & 60.67 & 0.082 \\
\hline Complications & 1502 & 36.37 & 1035 & 36.69 & 410 & 39.42 & 0.13 \\
\hline Diagnosis & 1226 & 29.68 & 858 & 30.41 & 358 & 34.42 & 0.019 \\
\hline Methods & 1195 & 28.93 & 809 & 28.68 & 189 & 18.17 & $<0.001$ \\
\hline Diagnostic imaging & 954 & 23.1 & 645 & 22.86 & 220 & 21.15 & 0.52 \\
\hline Adverse effects & 727 & 17.6 & 441 & 15.63 & 136 & 13.08 & 0.21 \\
\hline Pathology & 683 & 16.54 & 437 & 15.49 & 162 & 15.58 & 0.89 \\
\hline Injuries & 504 & 12.2 & 377 & 13.36 & 120 & 11.54 & 0.43 \\
\hline Therapy & 432 & 10.46 & 251 & 8.9 & 103 & 9.9 & 0.89 \\
\hline Prevention \& control & 385 & 9.32 & 254 & 9 & 102 & 9.81 & 0.97 \\
\hline Therapeutic use & 347 & 8.4 & 225 & 7.98 & 100 & 9.62 & 0.62 \\
\hline Epidemiology & 293 & 7.09 & 148 & 5.25 & 68 & 6.54 & 0.14 \\
\hline Abnormalities & 292 & 7.07 & 142 & 5.03 & 149 & 14.33 & $<0.001$ \\
\hline
\end{tabular}

\section{Qualifiers}

The most common qualifiers were "Surgery" and "Etiology." The qualifiers "Surgery" and "Methods" were significantly more common in CSF rhinorrhea, whereas "Abnormalities" was significantly more common in CSF otorrhea (Table 3).

\section{Generic MeSH Terms}

Table 4 shows the frequency of MeSH terms referring to human/animal research, female/male, age groups and type of study, in all CSF documents and by type of CSF. Most research was in humans. The proportion of documents relating to males and females is similar in CSF rhinorrhea and CSF otorrhea. By age, the terms "Infant," "Newborn," "Adults," "Young Adult," and "Middle Aged" are more common in CSF 
rhinorrhea; and the terms "Infant," "Child, Preschool," "Child," and "Adolescent" were significantly more common in CSF otorrhea. The most common MeSH terms describing the type of study was "Retrospective Studies" and "Follow-Up Studies," with similar results in both types of CSF.

Table 4

Distribution of medical subject headings (MeSH) referring to type of research, gender, age group and type of study on cerebrospinal fluid (CSF) leak, CSF rhinorrhea and CSF otorrhea (1945-2018)

\begin{tabular}{|c|c|c|c|c|c|c|c|}
\hline \multirow{2}{*}{ MeSH terms } & \multicolumn{2}{|c|}{ All documents * } & \multicolumn{2}{|c|}{ CSF rhinorrhea } & \multicolumn{2}{|c|}{ CSF otorrhea } & \multirow[t]{2}{*}{$P$ value } \\
\hline & $\mathrm{N}$ docs & $\%$ docs & $\mathrm{N}$ docs & $\%$ docs & $\mathrm{N}$ docs & $\%$ docs & \\
\hline \multicolumn{8}{|l|}{ Type of research } \\
\hline Humans & 889 & 97.91 & 2781 & 98.58 & 1029 & 98.94 & 0.42 \\
\hline Animals & 25 & 2.75 & 41 & 1.45 & 11 & 1.06 & 0.42 \\
\hline \multicolumn{8}{|l|}{ Gender } \\
\hline Female & 601 & 66.19 & 1598 & 56.65 & 576 & 55.38 & 0.52 \\
\hline Male & 594 & 65.42 & 1549 & 54.91 & 533 & 51.25 & 0.20 \\
\hline \multicolumn{8}{|l|}{ Age group } \\
\hline Infant, Newborn & 8 & 0.88 & 118 & 4.18 & 18 & 1.73 & $<0.001$ \\
\hline Infant & 51 & 5.62 & 118 & 4.18 & 125 & 12.02 & $<0.001$ \\
\hline Child, Preschool & 75 & 8.26 & 250 & 8.86 & 210 & 20.19 & $<0.001$ \\
\hline Child & 117 & 12.89 & 453 & 16.06 & 288 & 27.69 & $<0.001$ \\
\hline Adolescent & 164 & 18.06 & 578 & 20.49 & 246 & 23.65 & 0.023 \\
\hline Adult & 432 & 47.58 & 1351 & 47.89 & 379 & 36.44 & $<0.001$ \\
\hline Young Adult & 179 & 19.71 & 187 & 6.63 & 34 & 3.27 & $<0.001$ \\
\hline Middle Aged & 479 & 52.75 & 1280 & 45.37 & 355 & 34.13 & $<0.001$ \\
\hline Aged & 304 & 33.48 & 636 & 22.55 & 230 & 22.12 & 0.80 \\
\hline Aged, 80 and over & 112 & 12.33 & 140 & 4.96 & 46 & 4.42 & 0.93 \\
\hline \multicolumn{8}{|l|}{ Type of study } \\
\hline Retrospective Studies & 297 & 32.71 & 451 & 15.99 & 157 & 15.10 & 0.53 \\
\hline Follow-Up Studies & 111 & 12.22 & 272 & 9.64 & 96 & 9.23 & 0.61 \\
\hline Cohort Studies & 23 & 2.53 & 32 & 1.13 & 7 & 0.67 & 0.21 \\
\hline
\end{tabular}

* The totals in this column are smaller than those of CSF rhinorrhea and CSF otorrhea, because a one documents can be included in both $\mathrm{MeSH}$ 


\section{Visual representation of the network of MeSH terms}

Figure 2a maps the general visual representation of the field under analysis, with the main MeSH terms and their ties. Among the most important links were "Treatment Outcome" and "Postoperative Complications" with "Reconstruction Surgical Procedure," and with regard to diagnosis, "Tomography, XRay Computed" and "Magnetic Resonance Imaging." In CSF rhinorrhea, the most important MeSH terms were "Tomography, X-Ray Computed," "Endoscopy," and "Postoperative Complications" (Fig. 2b). In CSF otorrhea the most important were "Tomography, X-Ray Computed," "Retrospective Studies," "Treatment Outcome," and "Tempore Bone" (Fig. 2c).

\section{Discussion}

The number of articles published on CSF increased throughout the study period, which is normal, as most bibliometric analyses on other diseases also reveal an upward trend in the number of publications $[3,13$, 10]. The most significant aspect to point out is the predominance of case reports (approx. 35\%), which show similar values as for other surgical areas, such as maxillofacial surgery (31\%) [10]. Individually, case reports are insufficient grounds on which to base treatment decisions, but when they are considered together and adequately codified and integrated into structured information systems, they can provide early insight toward characterizing rare diseases, as they allow physicians to compare cases and check diagnoses [5].

At a journal level, this study shows the important multidisciplinary approach in the area, as the three most prominent publications are journals of otorhinolaryngology, surgery, and clinical neurology. The multidisciplinary approach of the science is a scientific reality that has been associated with greater advances in knowledge, translation of results, and impact of research $[4,6]$.

The USA was the predominant country in research production, followed by various European countries (UK, Germany, France and Italy) and Japan. This situation is also apparent in the otolaryngology field [3, $17,18]$, neurosurgery $[2,15,16]$, as in other health sciences $[3,10]$. The top countries did not include any from Africa, while the only Latin American country was Brazil. The top-contributing Asian countries (in addition to Japan) were India, China, and South Korea, while Turkey ranked eighth. A combination of factors can explain these observations. First of all, the USA emerges as the main point of reference in CSF, reflecting its global leadership in all scientific research spheres. Furthermore, the need to have a surgical structure to produce research in this field would favor the most developed countries to a greater extent $[3,7,18]$.

The level of international collaboration was very low (6.21\%), which highlights the need to develop surgical structures that favor the promotion of research in countries with less scientific development and implement strategies that favor multidisciplinary collaboration [4]. 
With regard to the MeSH terms, CSF rhinorrhea was the main branch, while surgery and postoperative complications were the most important sub-topics. Relevant topics related to managing patients with CSF were otorhinolaryngology and clinical neurology [21]. Research also focused on identifying risk factors and assessing different treatments and their outcomes, as shown by the terms related to etiology ("Skull Fracture" of "Skull Base"), diagnosis (especially via "Tomography, X-Ray Computed" or "Magnetic Resonance Imaging"), treatment ("Treatment Outcome" or "Endoscopy"), and complications (meningitis).

There is difference in the patient profile of research in CSF rhinorrhea and CSF otorrhea, with the former area concentrating on older patients ("Adult" or "Middle Age"). Spontaneous CSF rhinorrhea is associated with increased intracranial pressure and considered a manifestation of idiopathic intracranial hypertension in middle-aged people, whereas secondary CSF rhinorrhea is associated with trauma in the same age group [12]. On the other hand, CSF otorrhea research focused on the "Infant," "Child, Preschool," "Child" and "Adolescent" age groups, reflecting the fact that CSF otorrhea can be primary and in most of cases is secondary to pediatric skull base fractures [19]. Thus, even though CSF rhinorrhea and CSF otorrhea are included under the same umbrella MeSH term, the profile of research is quite different in these sub-fields.

The main limitation of this study was that we did not analyze citations, with a focus on the journals with the highest impact and dissemination at an international level; this perspective would be necessary to reach a truly comprehensive view of research in the field. [10] Likewise, other aspects could also be considered, such as co-authorship networks or gender disparities in scholarly productivity $[6,18]$

\section{Conclusion}

The present study has revealed some features that differ notably from bibliometric analyses on other clinical pathologies: the predominant interest in surgery and the weight of clinical case reports, which emerge as the primary channel for generating and disseminating knowledge in the field. Postoperative complications, diagnostic aspects related to computerized tomography and magnetic resonance imaging, treatment outcomes, and surgery procedures such as endoscopy were also topics of interest. The USA led research production, while European countries and emerging countries such as China contributed less than in other research areas.

\section{Abbreviations}

CSF: Cerebrospinal fluid

MeSH: medical subject headings

$\mathrm{MH}: \mathrm{MeSH}$ Terms

SH: MeSH Subheadings 
UK: United Kingdom

USA: United States of America

WOS: Web of Science

\section{Declarations}

\section{Ethics approval and consent to participate}

For this type of study formal consent is not required.

\section{Consent for publication}

All the authors give their consent for publication

\section{Availability of data and material}

J.M. Ramos-Rincon has full access to and is the guarantor for the data. The datasets generated are available from the corresponding author on reasonable request.

\section{Competing interests}

None declared

\section{Funding}

This study was no funded

\section{Authors' contributions}

Conceptualization: JMRR, GGA. Formal analysis: JMRR, IMC, JAO, JTGA, IBR and GGA. Methodology: JMRR, IBR, and GGA. Visualization: JMRR, IMC and GGA. Writing \pm original draft: JMRR, IMC and GGA, Writing \pm review \& editing: JMRR, IMC, JAO, JTGA, IBR and GGA. All authors have read and approved the manuscript

\section{Acknowledgements}

We gratefully acknowledge the assistance of Meggan Harris in the English language editing of our manuscript.

\section{References}

1. Akhaddar A (2019) African contribution to the World neurosurgical literature during the last two decades (1999-2018) using PubMed database. World Neurosurg 126:314-321 
2. Cheng W, Kang Q, Xiao Q (2019). Bibliometric Analysis of the Top 100 Influential Studies on Carotid Artery Stenting. World Neurosurg 122:e1321-e1331.

3. Encinas-Vicente A, Prim-Espada MP, Cenjor-Español C, de Diego-Sastre JI (2015) Impact of Otolaryngology theses in their authors' scientific production Acta Otorrinolaringol Esp 66:269-274.

4. González-Alcaide G, Park J, Huamaní C, Belinchón I, Ramos JM (2015) Evolution of Cooperation Patterns in Psoriasis Research: Co-Authorship Network Analysis of Papers in Medline (1942-2013). PLoS One10:e0144837.

5. González-Alcaide G, Peris J, Ramos JM (2017) Areas of research and clinical approaches to the study of liver abscess. World J Gastroenterol 23:357.

6. González-Alcaide G, Salinas A, Ramos JM (2018) Scientometrics analysis of research activity and collaboration patterns in Chagas cardiomyopathy. Dutra WO, editor. PLoS Negl Trop Dis 12:e0006602.

7. Guo X, Gao L, Wang Z, Feng C, Xing B (2018). Top 100 Most-Cited Articles on Pituitary Adenoma: A Bibliometric Analysis. World Neurosurg 116:e1153-e1167.

8. Lenzi R, Fortunato S, Muscatello L (2016) Top-cited articles of the last 30 years (1985-2014) in otolaryngology - head and neck surgery. J Laryngol Otol 130:121-127.

9. May JS, Mikus JL, Matthews BL, Browne JD (1995). Spontaneous cerebrospinal fluid otorrhea from defects of the temporal bone: a rare entity? Am J Otol 16:765-771.

10. Nabil S, Samman N (2012) The impact of case reports in oral and maxillofacial surgery. Int J Oral Maxillofac Surg 4::789-796.

11. Ota HCU, Smith BG, Alamri A, Robertson FC, Marcus H, Hirst A, Broekman M, Hutchinson P, McCulloch P, Kolias A (2020. The IDEAL framework in neurosurgery: a bibliometric analysis. Acta Neurochir (Wien). doi: 10.1007/s00701-020-04477-5.

12. Perheentupa U, Kinnunen I, Grénman R, Aitasalo K, Mäkitie AA (2010) Management and outcome of pediatric skull base fractures. Int J Pediatr Otorhinolaryngol. 74:1245-1250.

13. Ramos JM, González-Alcaide G, Bolaños-Pizarro M (2013) Bibliometric analysis of leishmaniasis research in Medline (1945-2010). Parasit Vectors 6:55.

14. Ramos JM, González-Alcaide G, Gutiérrez F (2016) Análisis bibliométrico de la producción científica española en Enfermedades Infecciosas y en Microbiología. Enferm Infecc Microbiol Clin 34:166176.

15. Ramos MB, Teixeira MJ, Preul MC, Spetzler RF, Figueiredo EG (2019). A Bibliometric Study of the Most Cited Reports in Central Nervous System Arteriovenous Malformations. World Neurosurg 129:261-268.

16. Samanci Y, Samanci B, Sahin E (2019) Bibliometric analysis of the top-cited articles on idiopathic intracranial hypertension. Neurol India 67:78-84.

17. Saunders TFC, Rymer BC, McNamara KJ (2017) A global bibliometric analysis of otolaryngology: Head and neck surgery literature. Clin Otolaryngol 42:1338-1342. 
18. Sun GH (2012) Bibliometric analysis of health services research in otolaryngology journals. Otolaryngol Head Neck Surg 147:841-847.

19. Teachey W, Grayson J, Cho D-Y, Riley KO, Woodworth BA (2017) Intervention for elevated intracranial pressure improves success rate after repair of spontaneous cerebrospinal fluid leaks. Laryngoscope 127:2011-2016.

20. Vioque J, Ramos JM, Navarrete-Muñoz EM, García-de-la-Hera M (2009) A bibliometric study of scientific literature on obesity research in PubMed (1988-2007). Obes Rev 11:603-611.

21. Waltman L, van Eck NJ, Noyons ECM (2010). A unified approach to mapping and clustering of bibliometric networks 4:629-635.

22. Wax MK, Ramadan HH, Ortiz O, Wetmore SJ (1997) Contemporary management of cerebrospinal fluid rhinorrhea. Otolaryngol Head Neck Surg 116:442-449.

23. Zagzoog N, Attar A, Reddy K (2018) The 50 most cited publications in endoscopic third ventriculostomy: a bibliometric analysis. J Neurosurg Pediatr 23:145-152. cerebrospinal fluid leaks. Laryngoscope 127:2011-2016.

\section{Figures}

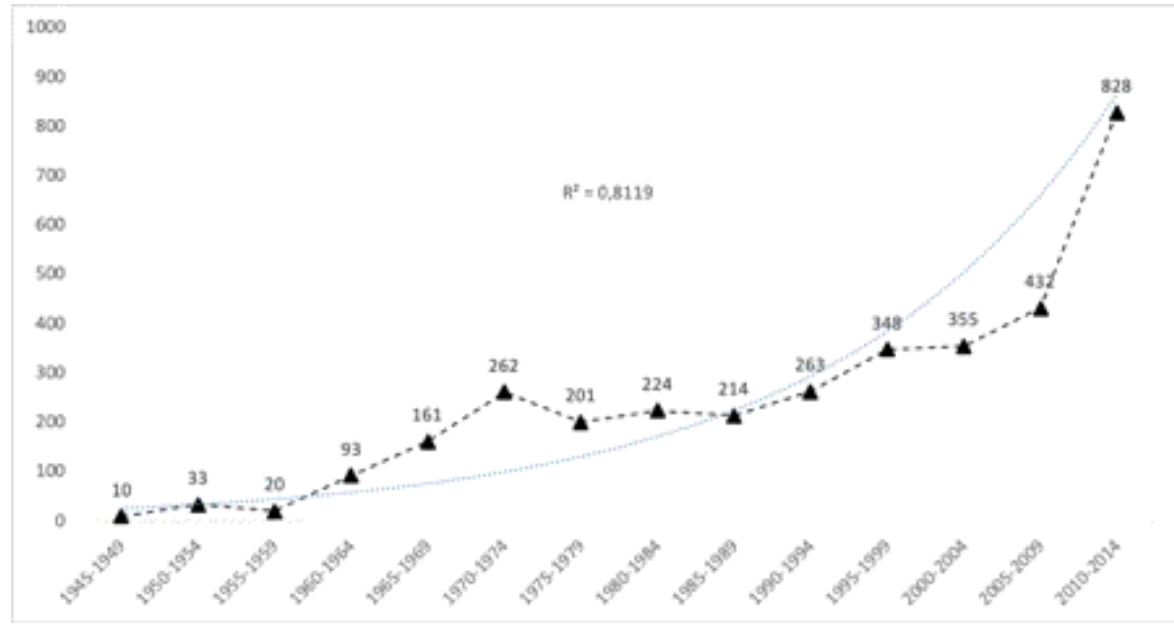

\section{Figure 1}

Evolution of number of documents published on cerebrospinal fluid leak by 5-year period* * The number of documents indexed in 2015-2018 period was 686 (lower because it is a four-year period and time lags in indexing the documents of the most. 


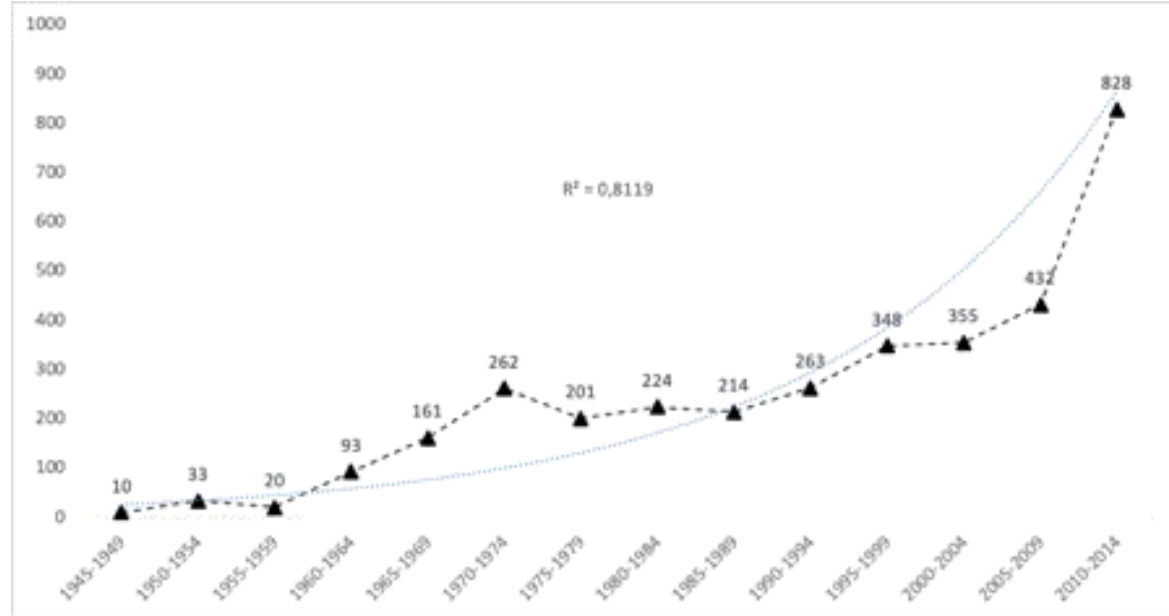

\section{Figure 1}

Evolution of number of documents published on cerebrospinal fluid leak by 5-year period* * The number of documents indexed in 2015-2018 period was 686 (lower because it is a four-year period and time lags in indexing the documents of the most. 


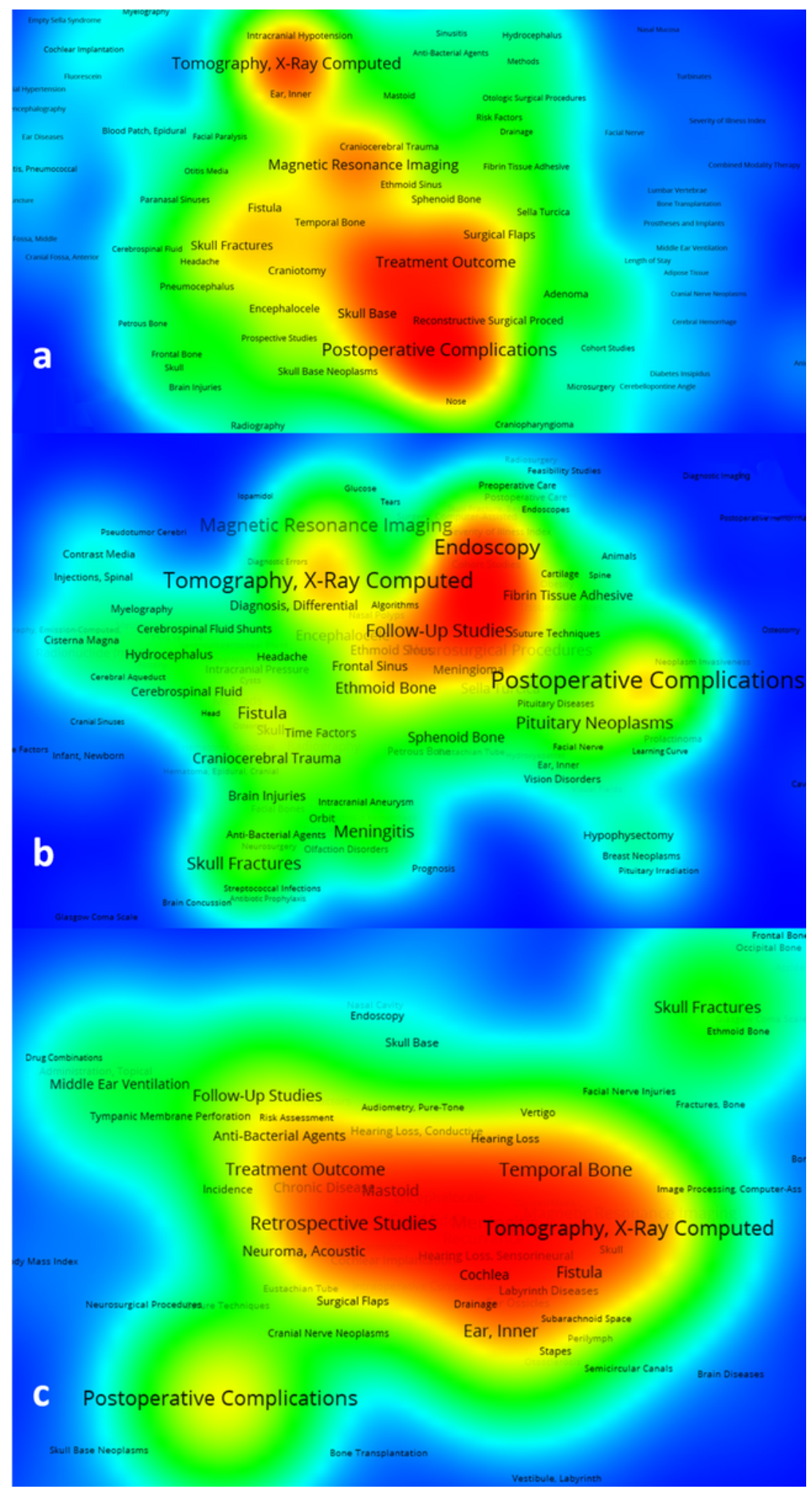

\section{Figure 2}

Analysis of topic clusters according MeSH assigned to publications (a) on cerebrospinal fluid (CSF) leak, (b) CSF rhinorrhea, and (c) CSF otorrhea Footnote: The different groupings, in the form of "islands" in red tones, represent the main clusters of the thematic networks, while the chromatic gradation illustrates the areas with a lower density of relations between the MeSH in yellow and green tones. The spatial 
distribution of the MeSH and their proximity to each other responds to the intensity of co-occurrence between them.

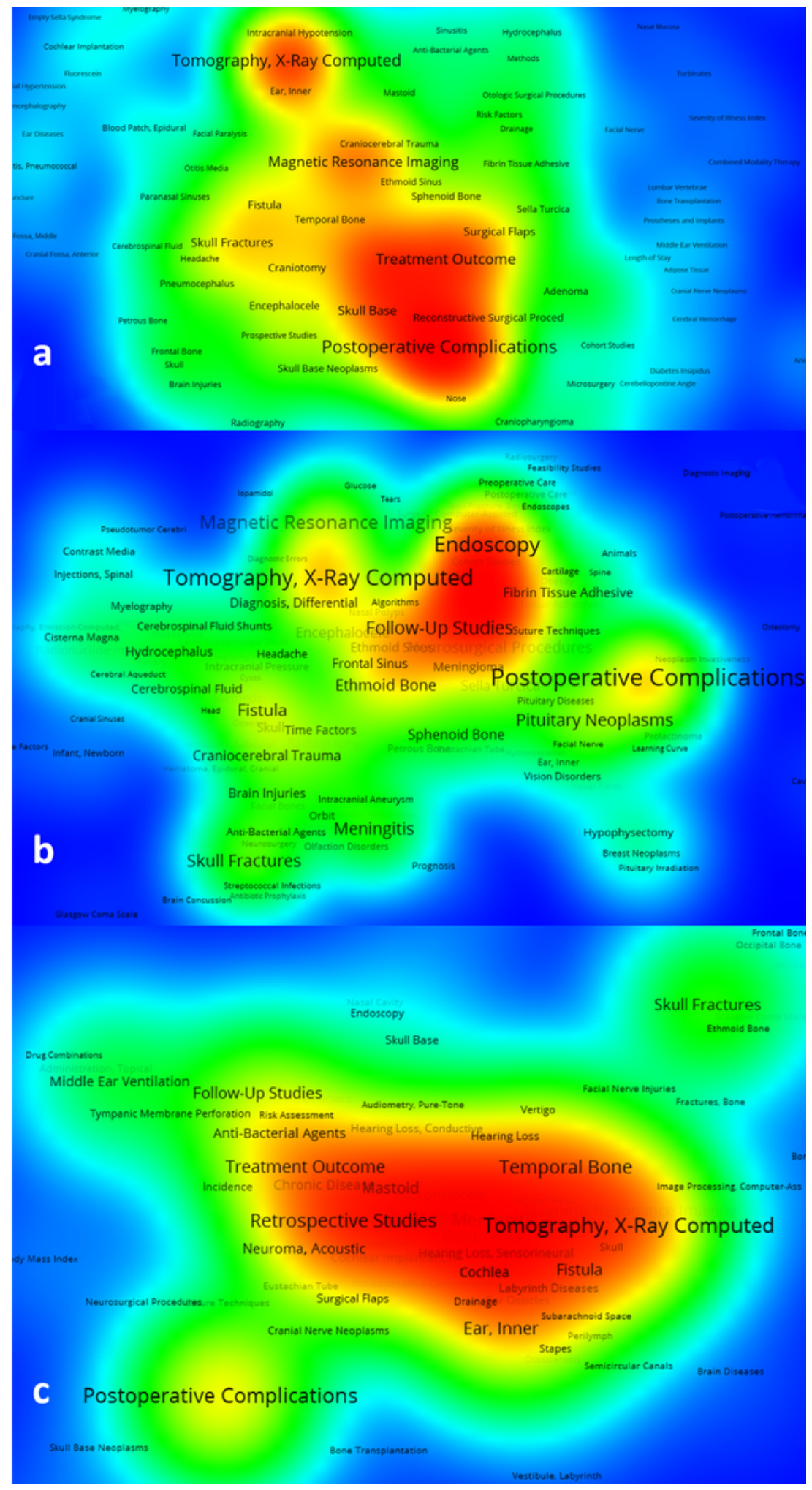

\section{Figure 2}

Analysis of topic clusters according MeSH assigned to publications (a) on cerebrospinal fluid (CSF) leak, (b) CSF rhinorrhea, and (c) CSF otorrhea Footnote: The different groupings, in the form of "islands" in red tones, represent the main clusters of the thematic networks, while the chromatic gradation illustrates the 
areas with a lower density of relations between the MeSH in yellow and green tones. The spatial distribution of the MeSH and their proximity to each other responds to the intensity of co-occurrence between them.

\section{Supplementary Files}

This is a list of supplementary files associated with this preprint. Click to download.

- BSURD2001336PRISMA.doc

- BSURD2001336PRISMA.doc 